\title{
ANGLICISMOS EN LA PRENSA DEPORTIVA DE PRINCIPIOS DEL SIGLO XX Y XXI: ESTUDIO CONTRASTIVO
}

\author{
María VÁzQUEZ-AMAdOR \\ Universidad de Cádiz \\ maria.vazquez@uca.es \\ M. Carmen Lario-De-OÑate \\ Universidad de Cádiz \\ carmen.lario@uca.es
}

\section{RESUMEN}

El deporte es hoy en día un fenómeno social de enorme relevancia en el mundo. El lenguaje deportivo está cargado de voces procedentes de otras lenguas ya que el léxico es la parte de la lengua que cambia más rápidamente al estar en continua evolución y expansión. El flujo de anglicismos en el ámbito deportivo queda patente en la prensa publicada desde principios del siglo xx y continúa afectando a nuestra lengua en la actualidad. El objetivo de este trabajo es conocer la evolución que han experimentado los anglicismos deportivos en el último siglo mediante un estudio comparativo de dos corpus lingüísticos conformados a partir de la recopilación de los anglicismos encontrados en diversos ejemplares del periódico Mundo Deportivo publicados a principios del siglo xx (1906-1910) y del siglo XXI (2010). Se analizarán los anglicismos de ambas muestras y se observará si han desaparecido, cuáles se mantienen, el predominio del uso en un deporte concreto y la presencia de anglicismos en voces deportivas generales. Asimismo se estudiará su admisión en el Diccionario de la Lengua Española. Los resultados del análisis contrastivo entre ambos corpus muestran que aunque la influencia de la lengua inglesa era ya evidente a principios del siglo xx, los anglicismos no sólo se han incrementado en número en el transcurso del tiempo sino que también se ha ampliado su espectro temático.

PALABRAS CLAVE: léxico; terminología; lenguaje deportivo; anglicismos. 


\section{Abstract}

Sport is an extremely relevant social phenomenon throughout the world today. The language of sport is full of words from other languages because lexis is the part of language that undergoes most changes due to contact with other languages. However, the presence of loanwords from English in sport is not a new incident, as is evident in the press published at the beginning of the $20^{\text {th }}$ century. The aim of this paper is to present the development of Anglicisms through a comparative analysis of both corpora taken from a sports newspaper dating from the beginning of the $20^{\text {th }}$ century (1906-1910) and the $21^{\text {st }}$ century (2010). The analysis consists of a comparison of those sports loanwords missing nowadays, those still in use, their frequency, and the prevalence of specific sports Anglicisms and those referring to general sports terms. In addition the admission in the Diccionario de la Lengua Española will be researched. The results show how the influence of English loanwords has increased over the last century, not only in number but also in the topics involved.

KEY WORDS: lexis; terminology; sports language; anglicisms; loanwords.

\section{INTRODUCCIÓN}

Uno de los aspectos en los que se manifiesta la gran proyección de la lengua inglesa es a través de los préstamos lingüísticos que entran en las distintas lenguas, los denominados anglicismos. Por anglicismo entendemos las voces de procedencia inglesa que otras lenguas adoptan, normalmente para nombrar un concepto desconocido o por otra serie de causas lingüísticas como el uso de sinónimos y efectos estilísticos.

Aunque la mayor parte de los autores sitúan la introducción de los anglicismos en lengua castellana después de la Segunda Guerra Mundial, son varios los investigadores que consideran que los anglicismos comenzaron a integrarse en la lengua española desde el siglo anterior (Rodríguez González, 1999).

Uno de las más importantes vías de penetración de los préstamos lingüísticos en la lengua receptora es a través de la prensa.

Los medios de comunicación actúan como aportadores y difusores de términos extranjeros, sobre todo por la traducción de las noticias llegadas a través de agencia y que generalmente aparecen redactadas en inglés. Este hecho se observa especialmente en la prensa (Giralt Latorre, 1991:138).

Algunos autores no sólo ven la prensa como vehículo de transmisión de anglicismos, sino que la consideran el eslabón que vincula el lenguaje especializado, del que provienen una gran parte de los anglicismos, y el lenguaje general, y favorece que éstos puedan propagarse y llegar al gran público. Los medios de comunicación escritos tienen la capacidad de difundir, de manera generalizada, información de carácter especializado utilizando para ello la terminología referente a cada campo de especialidad, de esta manera se van incorporando al léxico general (Cabré, 2005).

El periodismo especializado surge como una necesidad que tiene el público de saber, sus distintas especialidades son fruto del deseo del público de conocer los cambios que afloran en 
los distintos campos del saber (Edos, 1999). Se trata de trasladar a la sociedad información relativa a ciertos campos de especialidad como el económico, el médico o el deportivo entre otros. Este tipo de periodismo especializado favorece las vías de penetración de términos que surgen en los respectivos campos y saltan a la sociedad a través de las plumas de los periodistas $^{1}$. El periodismo deportivo ha sido definido como el lazo de unión entre los medios y el deporte (Molina, 2009). Por diversos motivos, que se tratarán a continuación, el lenguaje especializado relativo al deporte tiene entre sus características la alta presencia de voces extranjeras procedentes del inglés.

Los primeros pasos de este léxico técnico-especializado hay que buscarlos en la lengua del país donde ha nacido el deporte en cuestión, ya que en dicho idioma se redactaron los primeros reglamentos. Y la cuna de la mayoría de los deportes modernos es Gran Bretaña y Estados Unidos, con lo que la lengua anglosajona será la nodriza de tales términos (Guillem, 2011:171-172).

El deporte moderno nació en la Inglaterra del siglo xIX y no tardó en extenderse por el resto de Europa, llegando a España a finales de este siglo cuando los miembros de las clases acomodadas comenzaron a practicarlo (Rivero, 2004). El origen del periodismo deportivo se sitúa dentro de la crónica social de la prensa del siglo XIX a través de relatos sobre carreras de caballos, combates de boxeo, entre otros (Arango, 2005).

Entre las primeras publicaciones de prensa deportiva en España se encuentra Mundo Deportivo, que es, en la actualidad, la publicación más antigua aún vigente. Sus inicios datan de febrero de 1906 como semanario con el claro objetivo de difundir y exaltar la práctica del ejercicio físico, promocionando incluso campañas deportivas con el fin de lograr así la afición al deporte.

La presencia de los anglicismos en el mundo deportivo ha sido extensamente investigada por diversos autores (García Yebra, 1992; Lázaro Carreter, 1994; Alonso Pascual, 1996; Castañon, 1998; Nomdedeu-Rull y Márquez Rojas, 2001; Alvar, 2009; Lario y Vázquez, 2010; Rodríguez González, 2011; Torrebadella-Flix y Nomdedeu-Rull, 2013). El presente estudio investiga los anglicismos utilizados por Mundo Deportivo, en 1906-1910 y en 2010 con el objetivo de observar la evolución que éstos han sufrido durante el último siglo y percibir si se han producido cambios a nivel morfológico, léxico y semántico. Para ello se analizará la tipología a la que pertenecen los anglicismos de ambos corpus, las áreas temáticas con las que se relacionan y su aceptación en el Diccionario de la Lengua Española.

\section{DEFINICIÓN Y TIPOLOGÍA}

Como ya se mencionó anteriormente, los anglicismos son las voces de procedencia inglesa que se incorporan a otras lenguas generalmente para nombrar un concepto nuevo o por otra serie de causas lingüísticas como el uso de sinónimos y efectos estilísticos. En el momento en que los anglicismos se introducen en la lengua, su futuro es incierto, ya que éste depende de la popularidad que adquieran desde el momento de llegada, siendo un factor de suma importancia

${ }^{1}$ Claro ejemplo de ello fue en 1999 la incorporación del anglicismo unit link o unit linked (Lario de Oñate, 2002) 
su frecuencia de uso, cuanto más frecuentes, mayor será la probabilidad de instalarse en la lengua. «Pero hay muchos estados intermedios entre el rechazo total y la adopción total, y las modalidades en que la voz extraña encuentra acomodo dentro de la lengua anfitriona son bastante variadas» (Seco, 2000-2001:257). Por ello, cuando estas voces permanecen en la lengua receptora pueden mantener la grafía inglesa (e.g. strike), transformarse para asimilarse a las reglas ortográficas de ésta (e.g. boxeo procedente de la voz inglesa boxing) y en el caso de los vocablos bimembres traducirse como calcos léxicos (guardameta, procedente de la voz inglesa goalkeeper). A nivel semántico pueden conservar el significado original con el que llegaron a la lengua española o modificarlo con el paso del tiempo. Por el contrario, en otras ocasiones, la vida de estos anglicismos es efímera y desaparecen por caer en desuso o por ser sustituidos por vocablos autóctonos (e.g. linesman sustituido por juez de línea).

Dentro de la literatura sobre los anglicismos se pueden encontrar numerosas y muy diversas clasificaciones atendiendo a distintos criterios, como la necesidad de incorporación de éstos a la lengua (Alfaro, 1948); su frecuencia de uso (Lope Blanch, 1986 y López Morales, 1987); y criterios linguíísticos (Medina López, 1996). La mayoría de las clasificaciones son formales (Pratt, 1980; Lorenzo, 1987; Gómez Capuz, 1998; y Rodríguez Segura, 1999) y los autores se basan en las características ortográficas de los anglicismos y sus diferencias con las reglas de la lengua receptora para describirlos. La clasificación que aquí se presenta está basada principalmente en la tipología de Lorenzo (1987), que divide los anglicismos según el modo de su penetración en la lengua española y su grado de adaptación a ésta. Esta clasificación está basada en los hallazgos encontrados:

- Los anglicismos crudos son aquellos que conservan la grafía y pronunciación original, por ejemplo football, procedente de la voz inglesa football.

- Los anglicismos en período de aclimatación son vocablos cuya grafía o pronunciación está en proceso de adaptación a las normas españolas, aunque todavía mantienen elementos extranjeros, como sprintar, procedente de la voz inglesa sprint.

- Los anglicismos híbridos son fruto de la combinación entre el préstamo léxico y el calco, un claro ejemplo es alto standing.

- Los anglicismos totalmente asimilados son aquellas voces que en el pasado penetraron en el español directamente del inglés y hoy día ya están completamente integradas en el léxico español, un ejemplo lo encontramos en el verbo chutar, procedente del vocablo inglés shoot.

- Los calcos léxicos son aquellos préstamos que toman el significado y la estructura de la voz extranjera pero que se traducen a la lengua receptora, y están formados por más de una lexía, como es el caso de baloncesto, procedente de la voz inglesa basketball.

- Los falsos anglicismos son aquellas voces que, a pesar de tener apariencia inglesa, no existen en inglés como es el caso de puenting.

- Los anglicismos afrancesados son aquellos anglicismos que entraron en el español a través del francés, un claro ejemplo es la palabra rallye.

- Los préstamos semánticos son voces españolas que adquieren una nueva acepción por contagio de una voz inglesa con grafía similar, como ha ocurrido con el adjetivo casual. 


\section{METODOLOGÍA}

Para realizar este estudio se compararon dos corpus lingüísticos confeccionados a partir de la recopilación de los anglicismos localizados en ejemplares del periódico Mundo Deportivo publicado por primera vez en 1906 y vigente en la actualidad. Sus inicios datan de febrero de 1906 como semanario con el claro objetivo de difundir y exaltar la práctica del ejercicio físico, promocionando incluso campañas deportivas con el fin de lograr así la afición al deporte.

Un primer corpus comprende los anglicismos aparecidos en diez ejemplares del periódico Mundo Deportivo publicados entre 1906 y 1910 (Lario y Vázquez, 2010). Para investigar los anglicismos utilizados a principios del siglo XXI se analizaron los artículos del periódico Mundo Deportivo publicados durante 2010, los anglicismos utilizados en ellos conforman el segundo corpus. Para la recopilación de anglicismos se consideró el hecho de que se extrajeran del mismo número de páginas en cada uno de los dos corpus (1906-1910 y 2010) con el fin de que fuera una muestra equitativa de los anglicismos en prensa durante ambos periodos estudiados. Los ejemplares del periódico en sus inicios tenían 8 páginas de las cuales 2 estaban dedicadas a la publicidad. Se leyeron por tanto un total de 80 páginas del Mundo Deportivo para la elaboración de cada uno de los corpus, es decir, se analizaron 160 páginas del periódico en total. Tras la lectura de los textos, se registraron los anglicismos y se clasificaron según los criterios que a continuación se mencionan.

1. Tipología: Anglicismos crudos (e. g. shimmy); anglicismos en periodo de aclimatación (e. g. liftado); anglicismos asimilados (e. g. boxeo); calcos léxicos (e. g. juego limpio); anglicismos afrancesados (e.g. motocross); falsos anglicismos (e. g. sportman); anglicismos híbridos (e. g. tours guiados) y préstamos semánticos (e. g. dobles).

2. Áreas temáticas. Se distinguió entre voces relacionadas con un deporte concreto, voces deportivas generales y voces generales de otras áreas temáticas (periodismo, gastronomía, etc.).

3. Aceptación en las distintas ediciones del DRAE. Se anotó si el anglicismo era reconocido por el DRAE con la grafía con que se encontró en prensa o si lo hizo con otra grafía más acorde a las reglas de la lengua española. Para ello se utilizó el Nuevo Tesoro Lexicográfico de la Lengua Española (NTLLE), una herramienta que permite consultar todas las ediciones de los diccionarios de la RAE desde 1726. El NTLLE es un diccionario de diccionarios que contiene todo el léxico de la lengua española desde el siglo Xv hasta el Xx.

Una vez organizada toda esta información se han contrastado ambos corpus lingüísticos con el fin de determinar si se registran diferencias en los anglicismos localizados en las distintas fechas en cuanto a los criterios comentados con anterioridad. Seguidamente se pasó a la segunda fase del estudio que consistió en comprobar si los anglicismos encontrados en el corpus de 1910 se mantienen en la prensa deportiva actual, si se han aclimatado a las normas del español o, por el contrario, han desaparecido. Para ello se buscaron los anglicismos del corpus en todos los periódicos publicados desde el 1-1-2010 hasta el 3112-2010 mediante la herramienta de búsqueda que proporciona la Hemeroteca del Mundo Deportivo. 


\section{ANÁLISIS DE DATOS}

En el corpus de 1906-1910 se registraron 81 anglicismos, dato bastante inferior al obtenido en el corpus de 2010, con 127 anglicismos encontrados. Se han cuantificado los derivados y las distintas grafías aunque no se han considerado los plurales de palabras ya clasificadas.

En cuanto a la tipología formal de los anglicismos y como se aprecia en la tabla 1, la mayoría de éstos son crudos en ambos corpus y hay un porcentaje bastante aceptable de anglicismos asimilados, que es algo más alto en el corpus de 2010. En cambio, es significativo que el porcentaje de anglicismos en periodo de aclimatación es bastante más alto en el corpus de 1906-1910, probablemente por ser estos anglicismos en aquel momento vocablos recientemente incorporados a la lengua española y que aún no habían tenido tiempo de asimilarse a ésta. En el corpus 2010 se encuentra una mayor variedad en cuanto a la tipología formal de los anglicismos ya que se han podido localizar calcos léxicos, afrancesados, un híbrido y un préstamo semántico. A continuación se muestran los porcentajes calculados sobre el número total de anglicismos encontrados en cada corpus.

Tabla 1. Porcentaje según la tipología de los anglicismos

\begin{tabular}{|l|c|c|}
\hline \multicolumn{1}{|c|}{ Tipología } & Corpus 1906-1910 & Corpus 2010 \\
\hline Crudo & $72,9 \%$ & $74,8 \%$ \\
\hline Asimilado & $12,3 \%$ & $14,2 \%$ \\
\hline En periodo de Aclimatación & $9,9 \%$ & $3,9 \%$ \\
\hline Calco Léxico & & $3,1 \%$ \\
\hline Afrancesado & & $1,6 \%$ \\
\hline Híbrido & & $0,85 \%$ \\
\hline Préstamo Semántico & & $0,85 \%$ \\
\hline Falso anglicismo & $4,9 \%$ & $0,85 \%$ \\
\hline
\end{tabular}

En cambio, no se encontró gran variedad entre los anglicismos del corpus de 1906-1910. De los 81 anglicismos encontrados 62 son anglicismos crudos, es decir, el 72,9\% (back, bobs, bobs sleigh, bow window, boxing, cheque, club, confort, corner, cracks, cricket, dribling, flyer, foot-ball, freekick, goal, goal keeper, golf, handicap, hockey, interview, jockey, juniors, knockout, lawn tennis, leader, linecks, linesman, match, meeting, off-line, penalty, performance, rails, record, referee, reporter, ring, rounds, rugby, scratch, shoot, show, skating rink, sport, sprinter, stand, starter, stock, swing, tailors, tandem, team, tennis, tourings, tyre, water-closet y yacht). A continuación se muestra un fragmento en el que se nombran diversas de estas voces, en esta ocasión relacionadas con el fútbol.

A su solo anuncio aumentaron considerablemente los socios de los Clubs de Foot-Ball. [...] Los campos de juego se marcaron reglamentariamente, los referees hacían cumplir las leyes del juego al pie de la letra...[...] se jugó el match más interesante que se ha presenciado en Madrid. 
[...], pues tiró varios corners, atacó mucho, y dió ocasión al goal-keeper contrario para que demostrase lo mucho que valía (Mundo deportivo, 31-01-1907:4).

El 12,3\% de los anglicismos están asimilados a la lengua española (atletismo, automobilismo, autómovil, automovilismo, boxeador, boxear, boxeo, intervievar, mitin y yate) y el 10\% están en proceso de aclimatación (athletico, athletismo, foot-ballistas, footballístico, sportivo, stok, tourismo y yating). En siguiente ejemplo se muestran tres de ellos.

[...] me apresté á intervievar á quien es en ello maestro, tan pronto como tuve la satisfacción de estrecharle entre mis brazos. [...] le acosaron a preguntas, para inquirir aquello que más nos interesaba conocer, relacionado con estas cosas del sport que son nuestra eterna pesadilla. [...] He saludado á todos aquellos queridos amigos ciclistas, automovilistas, gimnastas, foot-ballistas, entusiastas todos del sport (Mundo deportivo, 28-01-1909:1).

Asimismo se encontraron cuatro falsos anglicismos, todos formados por la lexía "-man" ex-recordman, recordman, rowingman y sportman, el cual se encontró junto a otros anglicismos en el siguiente texto.

Interview? nada más lejos de nuestro ánimo; una visita de atención y cortesía al alcalde sportman, para ofrecerle nuestra modestísima publicación. [...] Planes y proyectos sportivos, realmente el Sr. Marqués de Marianao aún siendo sportman, antes que Alcalde, no ha tenido tiempo de trazárselos (Mundo deportivo, 01-02-1906:2).

Entre los anglicismos pertenecientes al corpus de 2010 se observa mayor variedad tipológica. Siguen predominando los anglicismos crudos, 95 de los 127 anglicismos de este corpus lo son, representando el 74,8\% (aces, air 10', airbag, alley oop, aussie, basket, big bang, bluetooth, box, break, cash flow, CD, champions, cheerleader, chicane, club, corner, crack, cross, cyborgs, downtown, Dream Team, drive, engineering business, facebook, fan, feeling, fifa world player, film, flushing medows, full, golf, gospel, grand slam, gunners, handicap, hat trick, high-side, hockey, hospitality, indoor, internet, jersey, junior, kick, king, ko, majors, manager, master, mister, mp3, off road, ok, open, playoff, pole, prime time, pub, puzzle, qualifying, qualy, quizz, radio paddock, ranking, record, safety car, scooter, set, shimmy, show, slogan, smash, speaker, sports-man, sprint, sprinter, staff, stand, stand-by, strike, team, tests, boss, ticket, tie-break, top secret, top-10, top-ten, twiter, usb, warm up, web y wild cards). Un 14,2\% eran asimilados (comité, dólar, dopaje, dopar, gol, golazo, golea, goleador, golear, lider, liderar, liderato, misil, neoyorquino, penalti, poliester, poquer y tenis). Llama la atención el elevado número de anglicismos asimilados creados por derivación de un anglicismo, lo que demuestra en cierta manera la vitalidad de la lengua española. Uno de esos ejemplos lo encontramos, entre otros, en goleador.

El goleador del Ajax, que logró 35 tantos en la Eredivisie esta temporada que acaba de terminar y suma ya 74 tantos desde que llegó al Groningen procedente del Nacional de su país, sabe por terceras personas que su juego gusta al 'staff' técnico del Barça (Mundo deportivo, 1006-2010:6).

Asimismo se registraron cinco anglicismos en periodo de aclimatación (fútbol, futbolista, liftado, sprintar, watios), cuatro calcos léxicos (guarda, guardameta, centrocampista y juego limpio), dos anglicismos afrancesados (autocar y motocross), un anglicismo híbrido (tours guiados); un falso anglicismo (parking) y un préstamo semántico, dobles. 
Un dato revelador sobre la tipología de los anglicismos es la existencia de distintos anglicismos que provienen de la misma voz inglesa. En el corpus de 1906-1910 procedentes de athletism se encontraron el anglicismo en periodo de aclimatación athletismo y el asimilado atletismo y el asimilado atlético; de la voz inglesa automobile se registraron en prensa automovilismo, automobilismo y automovil; de bobsleigh aparecieron bob y bobsleigh; de boxing se encontraron boxing, boxeador, boxeo; de la voz inglesa interview se registraron el crudo y el asimilado intervievar; procedentes de sport aparecieron el crudo y el anglicismo en periodo de aclimatación sportivo; de la voz inglesa stock se registraron el crudo y el anglicismo en periodo de aclimatación stok; y procedentes de yacht se encontraron el crudo, el asimilado yate y el anglicismo en periodo de aclimatación yating. En el corpus de 2010, procedentes de dope, se registraron dopaje y doping; y de sprint, el crudo y el anglicismo en periodo de aclimatación sprintar.

También se encontraron anglicismos en distintos estadios de asimilación en cada uno de los corpus. La voz inglesa football derivó en los anglicismos football, footballista, footballistico en el corpus 1906-1910 y los ya asimilados fútbol y futbolista en el corpus 2010. Procedentes de goal se localiza en 1906 el crudo goal, mientras que en 2010 aparecen los anglicismos gol, golazo, golea y golear; de goalkeeper se registra en el corpus 1906 el anglicismo crudo y en 2010 guarda y guardameta. Procedentes de lawn tennis se encontraron en 1906 los crudos lawn tennis y tennis y en 2010 el asimilado tenis. De la voz leader en 1906 se encontró el crudo y ya en 2010 los asimilados lider, liderato y liderar; de meeting, en el siglo xx se registró el crudo y en el siglo XXI el asimilado mitín; de penalty se encontró el crudo en el siglo xx y el asimilado penalti en el siglo XxI. Procedentes de sportsman, el corpus del siglo XX registró el falso anglicismo sportman y el del siglo XXI el crudo.

Otros anglicismos que coinciden en ambos corpus son club, corner, crack, golf, handicap, hockey, junior, record, rugby, show, sprinter, stand y team, todos ellos anglicismos crudos.

La tendencia general que se observa en cuanto a la tipología de los anglicismos coincidentes en ambos corpus es la asimilación de los mismos. El anglicismo crudo que se encuentra en el siglo xx se asimila ya en el siguiente siglo. En cambio, un menor grupo de anglicismos mantuvo la grafía original en ambos corpus, tratándose de voces muy conocidas y en su mayoría aceptadas en el diccionario.

Con respecto a las áreas temáticas de los anglicismos examinados se clasificaron como voces relacionadas con un deporte concreto, voces deportivas y voces generales. En el corpus de 1906-1910 se registraron 48 anglicismos relacionados con un deporte concreto, un 59,2\% siendo el fútbol y el boxeo los deportes con mayor número de anglicismos, como dribbling o knock-out; un 18,5\% de anglicismos eran voces deportivas, entre ellas crack y team; y el $22,2 \%$ restante lo representaban voces generales no relacionadas con el deporte, por ejemplo show y water-closet. En el corpus de 2010, sólo 50 de los 127 anglicismos estaban vinculados a un deporte en particular, el 39\%, siendo los más numerosos el fútbol y el tenis, con ejemplos como mister y set; un porcentaje de $12,5 \%$ correspondía a voces deportivas, entre ellas team e indoor; y curiosamente casi un 50\% de los anglicismos encontrados eran voces generales no relacionadas con el deporte, por ejemplo feeling y prime time. Como puede observarse en el gráfico que a continuación se presenta, casi el $80 \%$ de los anglicismos encontrados en el corpus de 1906-1910 están relacionados con el deporte, ya sea con uno concreto o con una voz deportiva más general. Este dato contrasta frontalmente con los encontrados 
en el corpus de 2010, en el que casi un 50\%, es decir, la mitad de los anglicismos son voces generales, como se muestra en el gráfico 1.

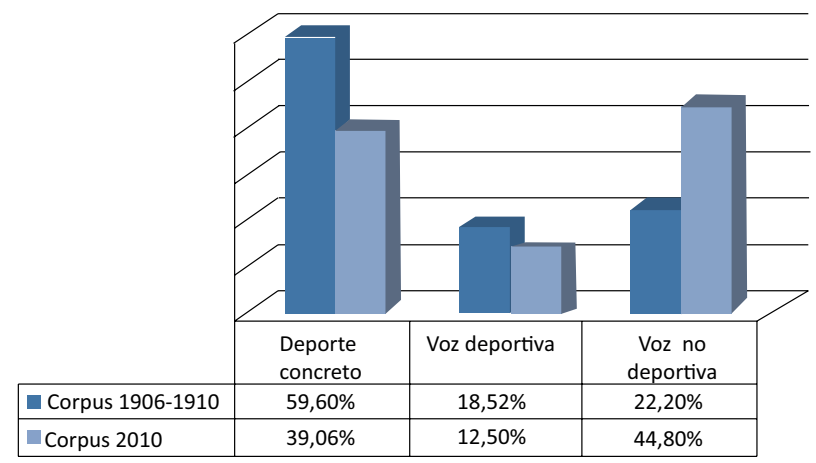

Gráfico 1. Porcentaje de las áreas temáticas de los anglicismos.

Tras contrastar ambos corpus, resulta muy interesante el escaso número de coincidencias en los anglicismos localizados, no sólo entre las distintas disciplinas deportivas (en el corpus 1906-1910 no hay anglicismos relacionados con el baloncesto y en el corpus 2010 con el boxeo) sino en el ámbito de cada una de ellas (entre los 15 anglicismos relacionados con el fútbol del corpus 1906 y 1910 y los 17 del corpus 2010, tan sólo cuatro son comunes), como se aprecia en la tabla 2.

Tabla 2. Coincidencia de los anglicismos en ambos corpus

\begin{tabular}{|l|c|c|c|}
\hline \multicolumn{1}{|c|}{ Disciplina } & Corpus $1906-1910$ & Corpus 2010 & Coincidencias \\
\hline Voces deportivas & 15 & 17 & 2 \\
\hline Voces no deportivas & 18 & 16 & 4 \\
\hline Fútbol & 15 & 12 & \\
\hline Automovilismo & 6 & & \\
\hline Boxeo & 8 & & \\
\hline Atletismo & 3 & & \\
\hline Navegación & 3 & 3 & 2 \\
\hline Tenis & 2 & 3 & \\
\hline Baloncesto & 11 & & \\
\hline Otros deportes & & & \\
\hline
\end{tabular}

Las mayores coincidencias encontradas son las voces deportivas. En la prensa del siglo $\mathrm{xx}$ se registraron los anglicismos club, crack, handicap, junior, leader, linecks, match, 
record, recordman, ex-recordman, sport, sportivo, sportman, sprinter y team y en la del siglo XXI crack, dopaje, dopar, handicap, hat trick, indoor, juego limpio, junior, playoff, record, sports-man, sprint, sprintar, sprinter, team, top-10, top-ten. Los anglicismos comunes en ambos corpus son crack, handicap, junior, record, sprinter y team. Asimismo coinciden dos anglicismos procedentes de la misma voz inglesa pero con distintas grafías, sportman (falso anglicismo) en el corpus de 1906-1910 y sportsman (anglicismo crudo) en el de 2010.

En cuanto a las voces no deportivas encontradas en el Mundo Deportivo del siglo xx (bow window, cheque, confort, intervievar, interview, meeting, mitin, performance, rails, reporter, show, stand, stock, stok, tailor, tourings, tourismo y water-closet) y las del siglo XxI (airbag, aussie, autocar, big bang, blue tooth, cash flow, CD, comité, cyborgs, dólar, downtown, engineering business, facebook, fan, feeling, film, full, gospel, gunners, hospitality, internet, jersey, king, k.o., lider, liderar, liderato, manager, misil, mp3, neoyorquino, ok, parking, poliester, poquer, prime time, pub, puzzle, qualifying, quizz, ranking, show, slogan, speaker, staff, stand, stand-by, tests, boss, ticket, top secret, tours guiados, twiter, usb, warm up, watios y web) se observa la revolución tecnológica sufrida en el siglo XXI, con un número muy alto de anglicismos relacionados con las nuevas tecnologías como twiter, facebook, $C D$ o usb. Los anglicismos que coincidieron en ambos corpus son show y stand, asimismo y procedentes de la misma voz inglesa, aunque en distintos estadios de asimilación, se encuentra en el siglo xx touring (anglicismo crudo) y en el siglo XXI tour guiados, híbrido procedente de la voz inglesa guided tour.

En ambos corpus el número de anglicismos vinculados con el fútbol fue bastante elevado, ya apuntaba como deporte rey desde el siglo xx. A pesar de ello, son pocas las voces que coincidieron en ambos corpus, normalmente con una grafía más acorde con la española, con la excepción de corner que mantiene con la misma grafía cruda en el siglo xx y XxI. El crudo football, localizado en el siglo Xx se asimila a fútbol en el siglo XXI, al igual que footballista, que aparece como futbolista en el siglo Xxi; goal que se asimila a gol en el siglo Xxi y penalty a penalti. Asimismo, el anglicismo crudo goalkeeper en el corpus del siglo xx se encuentra como calco léxico (guardameta) en el siglo XxI. Relacionados con el automovilismo se detectaron bastantes anglicismos tanto en el corpus del siglo xx (e. g. starter) como en el del siglo Xxi (e.g. safety car y shimmy) sin coincidir ninguno en ambos corpus. Los anglicismos vinculados al boxeo (e. g. ring y boxing), al atletismo y a la navegación tan solo se hallaron en el corpus del siglo xx. Por el contrario, los anglicismos relacionados con el mundo del tenis son mucho más frecuentes en el siglo XXI (e.g. tie break y strike) de igual manera que el baloncesto (e. g. cheerleader). En ambos corpus se hallaron anglicismos relacionados con otros deportes, sobre todo en el corpus del siglo xx, como ciclismo (tandem), cricket (cricket), golf (golf), hípica (jockey), hockey (hockey), patinaje (skating rink), remo (rowing men), rugby (rugby), deportes aéreos (flying), deportes de invierno (bobs y bobsleigh). En el corpus del siglo XXI tan sólo se localizaron dos anglicismos de otros deportes, que coincidían con los del siglo xx, son hockey y cricket. Este dato puede ser consecuencia de que a principios del siglo xx comenzó el boom de los deportes y aún no se sabía cuáles eran los que se convertirían en deportes consolidados dentro de la sociedad española y cuáles se convertirían en deportes minoritarios y por tanto con menos transcendencia en la prensa.

Con el fin de determinar la presencia de los anglicismos analizados en el Diccionario de la Lengua Española (DRAE) éstos se buscaron tanto en la penúltima edición del DRAE (2001) como en las ediciones anteriores del diccionario accesibles a través de Internet en el Nuevo 
Tesoro Lexicográfico de la Lengua. Los anglicismos no solo se rastrearon con la grafía con que aparecieron en prensa sino también con distintas grafías más asimiladas al español.

De los 81 anglicismos encontrados en Mundo Deportivo de 1906-1910, un total de 42 han sido admitidos en alguna de las distintas ediciones del DRAE con la misma grafía con la que se encontraron en prensa, el 51,9\%. El anglicismo club fue admitido ya desde la edición de 1837 con un significado relacionado con la política (Junta de individuos de alguna sociedad política clandestina); yacht se aceptó en 1869 y yate, anglicismo ya asimilado en 1884, al igual que rail. En la edición de 1899 vieron la luz automóvil y cheque; en 1914 automovilismo y mitin y en 1926 atletismo. Fue sin duda la edición de 1927 la que registró un número más alto de anglicismos (boxeador, boxear, boxeo, confort, foot-ball, golf, handicap, intervievar, jockey, leader, match, record, sport, sportman, tandem y water-closet). Interview se admitió en 1950, corner en 1983 y dribling, hockey y junior en 1984. La edición de 1985 también destaca por el número de anglicismos registrados: penalty, reporter, ring, rounds, rugby, show, stand, starter, stock swing y team. Estos anglicismos eran en su mayoría crudos aunque también se registraron en el diccionario algunos anglicismos asimilados. Siete de ellos ya no están vigentes en el DRAE. Intervievar tan sólo apareció en la edición del DRAE de 1927, definiéndose como "Neologismo inútil por conferenciar o entrevistar"; match se mantuvo en el diccionario hasta la edición de 1989; sportman tan sólo se registra en la edición de 1927 y la de 1989; dribling, round, swing y team en las de 1984 y 1989. Fueron 14 los anglicismos que se admitieron en el diccionario con una grafía más asimilada a la encontrada en prensa, el 17,3\%. Se trata principalmente de anglicismos en periodo de aclimatación y anglicismos crudos. Athletico se aceptó como "atlético" desde 1803, y athletismo como atletismo en 1926; automobilismo y meeting como "automovilismo" y "mitin" desde 1914; tourismo como "turismo" en 1925. En la edición de 1927 se registraron boxing como "boxeo" (m. Pugilato), goal como "gol", lawn tennis y tennis como "tenis". Footballista se admitió como "futbolista" en 1936 y footballistico como futbolístico en 1956; cricket como "criquet" en 1950; stok como "stock" en 1958; y shoot como "chutar" en 1989. Todos se mantienen en la edición de 2001 del diccionario. Veinticinco anglicismos no fueron admitidos en ninguna edición del DRAE, back y knock out entre otros. La mayor parte de ellos coinciden en ser crudos (flyer y freekick). Dos de estos anglicismos que sí se registran en la edición de 2001 del DRAE, son crack (deportista de extraordinaria calidad) y sprinter como "esprínter". A continuación se muestran los porcentajes en el siguiente gráfico.

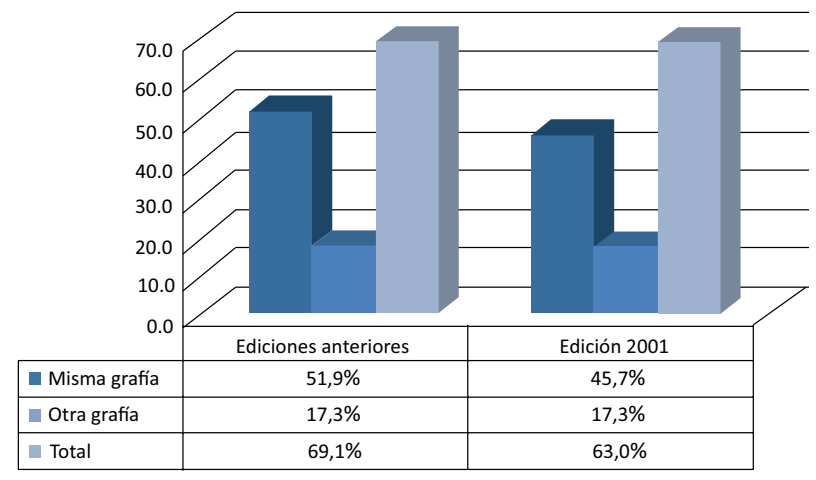

Gráfico 2. Porcentaje de anglicismos del corpus de 1906-1910 admitidos en el DRAE. 
De los 127 anglicismos del corpus de 2010, 59 anglicismos habían sido admitidos con la grafía encontrada en prensa, el 46,5\%. Club (1837), dólar y neoyorquino (1899) y comité (1925). Nuevamente la edición de 1927 registró un número bastante elevado de anglicismos, gol, fútbol, tenis, box, break, golf, handicap (voz inglesa. Se aspira la h). "Ventaja partido y especialmente carrera en que uno o más caballos obtienen una ventaja en tiempo, distancia o peso para igualar la partida"), jersey, mister, record, speaker y ticket. Futbolista se aceptó en 1936; poquer en 1947 y sportsman en 1950 como voz inglesa sinónimo de deportista. En la edición de 1970 se admitieron los anglicismos autocar, goleador, golear, líder, liderato, misil y guardameta; en 1983 centrocampista y corner; en 1984 motocross, fan, hockey, junior, manager y open; y en 1985 parking, poliester, pub, puzzle, ranking, set, show, slogan, sprint, staff, stand, team y test. En la edición 1989 se registraron liderar y master; y en la de 1992 dopaje, dopar, penalti, cross y film. Aunque había variedad tipológica, la mayor parte de los anglicismos registrados eran crudos y asimilados. La mayoría siguen presentes en la edición de 2001, tres de ellos después de un cambio de grafía, slogan que se registra como eslogan; ticket como "tiquet" y puzzle como "puzle". Seis terminaron desapareciendo del DRAE (break, pub, speaker, sportsman, staff y team). Tan sólo dos anglicismos se registraron en las ediciones anteriores del DRAE después de un cambio de grafía, watio como "vatio" en 1899 y basket admitido como básquet en 1992. El número de anglicismos que no han sido admitidos en ninguna edición del diccionario es bastante elevado, con un total de 67, mayoritariamente anglicismos crudos (e. g. hat trick y smash). Asimismo se encontró un grupo de ocho anglicismos que no fueron admitidos en ediciones anteriores aunque sí se registran en la edición de 2001 sin cambios en la grafía (airbag, web, CD, internet, big bang, crack, gospel y scooter) y 3 de ellos después de un cambio de grafía (feeling como "filin"; sprinter como "esprinter"; y sprintar como "esprintar"). A continuación se muestran los porcentajes de los anglicismos del corpus de 2010 admitidos en el DRAE.

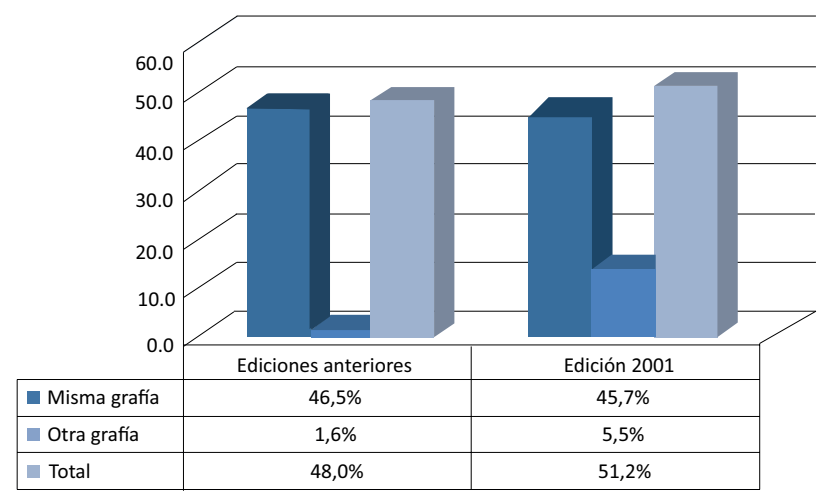

Gráfico 3. Porcentaje de anglicismos del corpus de 2010 admitidos en el DRAE.

Con el fin de comprobar si los anglicismos encontrados en el corpus de 1910 se mantienen en la prensa deportiva cien años más tarde, éstos se buscaron en todos los números publicados desde el 1-1-2010 hasta el 31-12-2010 mediante la herramienta de búsqueda de la hemeroteca del Mundo Deportivo. De los 81 anglicismos que se registraron en el corpus 
de 1910, la mayoría siguen presentes en la prensa deportiva actual: 45 de ellos manteniendo la grafía con la que se encontraron (bobs sleigh, handicap); 14 de estos anglicismos con una grafía más asimilada a las normas del español (goal como gol o boxing como boxeo); 16 de los anglicismos desaparecieron (frekick, skating rink); y 6 han permanecido como nombres propios de equipos de fútbol (Team McLaren) o nombres de periódicos (Guerin Sportivo).

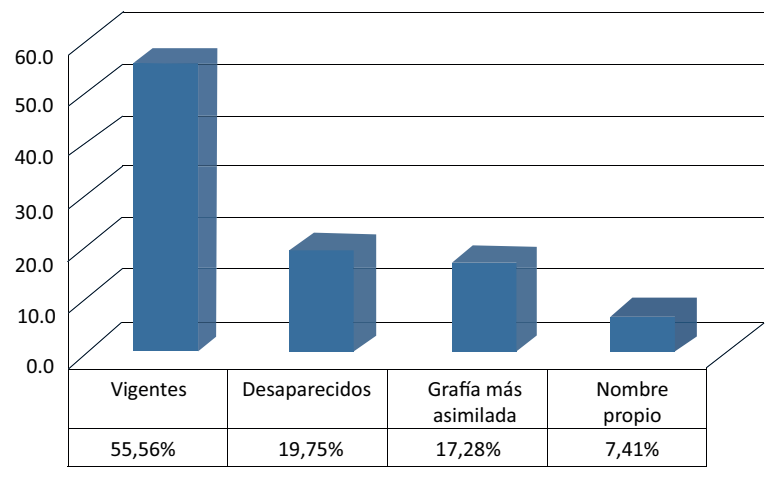

Gráfico 4. Porcentaje de anglicismos del corpus 1906-1910 en la prensa de 2010.

El gráfico evidencia la permanencia de esos vocablos que se introdujeron en la lengua española en su momento y su integración en la misma.

\section{CONCLUSIONES}

El estudio realizado sobre los anglicismos en el Mundo Deportivo de 1906-1910 y 2010 demuestra que la influencia de la lengua inglesa en el tecnolecto del deporte era ya evidente a principios del siglo $\mathrm{xx}$, consecuencia del origen angloamericano de la mayor parte de las prácticas deportivas que se iban introduciendo en España y que quedaban reflejadas a través de los anglicismos en los periódicos de la época. Este fenómeno se ha ido incrementando con el paso de los años y es aún más evidente en la muestra de periódicos analizados en el transcurso de 2010, cien años más tarde. El deporte, como muchos otros ámbitos, ha ido aceptando e incorporando esos nuevos vocablos al día a día deportivo.

Con respecto a la tipología de los anglicismos, se detecta una diversidad tipológica algo mayor en el corpus del siglo XXI, en el que se localizaron anglicismos crudos, asimilados, en periodo de aclimatación, afrancesados, híbridos, calcos léxicos y préstamos semánticos, mientras que en los periódicos del siglo xx tan sólo se hallaron anglicismos crudos, asimilados, en periodo de aclimatación y falsos anglicismos. Es sorprendente la similitud en los porcentajes de los anglicismos crudos y asimilados en los dos corpus y que constituían casi el $90 \%$ en ambos casos. Los anglicismos crudos son los más numerosos (el 72,9\% en el corpus del siglo xx y el 74,8\% en el del siglo xxI) probablemente por tratarse de vocablos nuevos que acababan de incorporarse a la lengua española o por tratarse de voces utilizadas internacionalmente y que no llegaron a asimilarse. Los anglicismos asimilados representaban 
el $12,3 \%$ en el corpus del siglo xx y el 14,2\% en el del siglo xxi y eran voces que estaban ya totalmente adaptadas a la lengua española. El porcentaje del resto de los tipos de anglicismos encontrados no eran representativos.

En cuanto a las áreas temáticas a las que pertenecen los anglicismos, el primer dato que destaca es que los periódicos deportivos más recientes tienen un número alto de anglicismos de un área general, casi la mitad, dato que contrasta con el de los periódicos deportivos de principios del siglo pasado, en los que la mayoría de los anglicismos estaban relacionados con el deporte en sí. Ello demuestra la enorme influencia de la lengua inglesa no sólo en ámbitos especializados sino también en áreas temáticas más generales. También resulta llamativo el reducido número de anglicismos que coincidieron en ambos corpus, tan solo catorce siendo la mayor parte voces deportivas. Mientras en 1906-1910 se registraron anglicismos relacionados con 16 deportes distintos, en la mayoría de los casos con una representación bastante baja, en el del siglo XXI tan sólo se registraron anglicismos vinculados a 6 deportes. En ambos corpus destacan los anglicismos relacionados con el fútbol, mientras en el resto de los deportes no se encuentran similitudes.

Con respecto a la admisión de los anglicismos en el DRAE, en el caso de los anglicismos del corpus de 1906-1910, este porcentaje es bastante más elevado, casi un 70\% entre los registrados con o sin cambios de grafía, mientras que los pertenecientes al corpus de 2010 no alcanzaban el 50\% entre los admitidos. Estos datos cobran sentido si tenemos en cuenta que los anglicismos registrados en 1906-1910 han tenido casi cien años para ser admitidos en el DRAE, mientras que muchos de los anglicismos registrados posteriormente son de nueva incorporación y aún, en su momento, no eran suficientemente frecuentes y populares como para ser aceptados en el DRAE.

La mayor parte de los anglicismos encontrados en el Mundo Deportivo de 1906-1910 siguen vigentes en la lengua española, dato que demuestra que estas voces llegaron a la lengua española fruto de la necesidad de nombrar un concepto que aún no existía en nuestra lengua. Es evidente la preponderancia de la lengua inglesa que se inició siglos atrás y que se ha ido incrementando debido a razones económicas, políticas, científicas, sociales, culturales y también lingüísticas.

\section{BIBLIOGRAFÍA}

Alfaro, Ricardo (1948): «El anglicismo en el español contemporáneo». Thesaurus, tomo 4, n 1, pp. 102-120.

Alonso Pascual, José (1996): Anglicismos deportivos: uso y abuso en la información española. Valladolid: Junta de Castilla y León.

Alvar EzQuerra, Manuel (2009): «El deporte y los términos deportivos». Coordinador, hernán-Gómez Prieto, Beatriz. Il linguaggio dello sport. La comunicazione e la scuola. Edizioni Universitarie di Lettere Economia Diritto (LED), pp. 149-166.

Arango Forero, Germán (2005): «Siglo XXI: hacia una nueva deontología del periodismo deportivo». Palabra Clave, vol. 8, n. $^{\circ}$ 2, pp. 13 -151.

Berasategui, María Luisa (2000): «Datos para la historia de la prensa deportiva en Cataluña». Revista General de Información y Documentación, vol., 10, n. ${ }^{\circ} 1$, pp. 153-169. 
Betz, Werner (1949): Deutsch und Lateinisch: die Lehnbildungen der althochdeutschen Benediktinerregel. Bonn: Bouvier.

CABRÉ, MARÍA TEResa (2005): La terminología: representación y comunicación: elementos para una teoría de base comunicativa y otros artículos. Barcelona: Institut Universitari de Lingüística Aplicada. Universitat Pompeu Fabra.

CAstañón Rodríguez, Jesús (1998): «Anglicismos hispánicos del deporte moderno», Apuntes..., vol. 6, n. ${ }^{\circ} 1$, pp. 9-11.

García Yebra, Valentín (1992): «Neologismos en la prensa deportiva». El neologismo necesario. Madrid, Fundación Efe, pp. 187-195.

Giralt Latorre, Javier (1991): «Algunos préstamos en el español de Panamá». Estudios de Lingüística de la Universidad de Alicante, n. ${ }^{\circ}$ 7, pp. 137-158.

Gómez Capuz, Juan (1998): El préstamo lingüístico: conceptos, problemas y métodos. Valencia: Universitat de Valencia.

Görlach, Manfred (1994): «The Usage Dictionary of Anglicisms in Selected European Languages». Links and letters, n. $^{\circ}$ 5, pp. 209-222.

HAUgen, Einar (1950): «The analysis of linguistic borrowing». Language, vol. 26, n. ${ }^{\circ}$ 2, pp. 210-231.

LaRio de OÑate, M. CARMEN (2002): «Origen y evolución de un nuevo anglicismo: Unit Link/ed». Lenguas para Fines Específicos (VII). Servicios Publicaciones U. Alcalá de Henares, pp. 143-148.

Lario de Oñate, M. Carmen y Vázquez Amador, María (2010): «Anglicismos y galicismos en El Mundo Deportivo de principios del XX». Files 9th International Conference of European Association of Languages for Specific Purposes. Hamburg, 19-22 septiembre 2010, pp. 1-9.

Lázaro Carreter, Fernando (1994): «El español en el lenguaje deportivo». El idioma español en el deporte. Madrid: Fundación EFE, pp. 19-35.

Lemus, Jorge (2006): «¿El mito del español amenazado?». Científica, n. ${ }^{\circ}$ 7, pp. 54-73.

LOPE BLANCH, JUAN (1986): «Anglicismos en el español del suroeste de los Estados Unidos». Editor, Neumeister, Sebastian. Actas del IX Congreso de la Asociación Internacional de Hispanistas. Frankfurt: Vervuert, pp. 131-138.

López Morales, Humberto (1987): «Anglicismos léxicos en el habla culta de San Juan de Puerto Rico». Lingüística Española Actual, vol. 9, n. ${ }^{\circ}$ 2, pp. 285-303.

Lorenzo, Emilio (1987): «Anglicismos en la prensa». Primera reunión de Academias de la Lengua Española sobre el lenguaje y los medios de comunicación. Madrid: Real Academia Española, pp. 71-79.

Medina LóPez, JAVIer (1996): El anglicismo en el español actual. Madrid: Arco-Libros.

Molina, Javier (2009): «Periodismo deportivo 3.0». Razón y palabra, n. ${ }^{\circ}$ 69. Disponible en http:// www.razonypalabra.org.mx/PERIODISMO\%20DEPORTIVO\%2030.pdf

Mundo Deportivo. Disponible en: http://www.mundodeportivo.com/hemeroteca

Nomdedeu-Rull, Antoni y Márquez Rojas, Melva (2001): «Los anglicismos en la terminología del fútbol: motivaciones y consecuencias lingüísticas». Coordinadora, Moreno Fernández, Ana Isabel. Perspectivas recientes sobre el discurso. AESLA. León: Universidad de León, pp. 5-22.

Pratt, Chris (1980): El anglicismo en el español peninsular contemporáneo. Madrid: Gredos.

Real Academia Española (2001): Diccionario de la Lengua Española. Madrid: Espasa Calpe. URL: http:// www.rae.es [01/05/2011].

Rivero Herraiz, Antonio (2004): «Los orígenes del deporte español: el desarrollo de un nuevo componente cultural urbano». Kronos, n. ${ }^{\circ}$ 6, pp. 29-33.

Rodríguez González, Félix (1999): «Anglicisms in Contemporary Spanish. An Overview». Atlantis, n. ${ }^{\circ} 21$, pp. 103-139.

- (2012): «Anglicismos en el mundo del deporte: variación lingüística y sociolingüística». Boletín de la Real Academia Española, Tomo 92, Cuaderno 306, pp. 317-341.

Rodríguez Segura, Delia (1999): Panorama del anglicismo en español: presencia y uso en los medios. Almería: Universidad de Almería. 
Rodríguez, Félix y Lillo, Antonio (1997): Nuevo diccionario de anglicismos. Madrid: Gredos.

Seco, Manuel (2000-2001): «La importación léxica y la unidad del idioma: anglicismos en Chile y en España». Boletín de Filología, BFUCh, XXXVIII, pp. 253-280.

Torrebadella-Flix, Xavier y Nomdedeurull, Antoni (2013): «Foot-ball, futbol, balompié... Los inicios de la adaptación del vocabulario deportivo de origen anglosajón». RICYDE. Revista Internacional de Ciencias del Deporte, vol. IX, núm. 31, enero, 2013, pp. 5-22. 